\title{
Improvement on geometric deflection rate formula of double-bent screw tool
}

\author{
Jianbin WANG ${ }^{1 \mathrm{a}}$, Hingshan Xiong ${ }^{1 \mathrm{~b}}$, Yan Zhang ${ }^{2 \mathrm{c}}$, Hongqing $\mathrm{Lu}^{3 \mathrm{~d}}$ \\ 1 Petroleum Engineering College of Yangtzue University, 430100; \\ 2 Earth Sciences of Yangtzue University, 430100; \\ 3 Nanning city in guangxi beibu gulf airlines co., LTD, 5350000。 \\ a460991414@qq.com, b1297228679@qq.com, c583515422@qq.com,d645123936@qq.com,
}

Keywords: Double-bent screw tool, Geometric deflection rate, Formula improvement, Descending well feasibility, Sensitivity analysis.

\begin{abstract}
To accurately predict and design deflection rate of screw tools is one of the key technologies to steering drilling. The artizaoxiel cle based on the principle of minimum potential energy, considered the influence of clearance between the side-wall and the stabilizer on deflection rate, gives a definition of additional deflection rate produced by influence of clearance. The original geometric deflection rate formula is improved. According to the actual data, using the new improved formula, we draw a conclusion that error between geometric and actual deflection rate is greatly reduced. Based on the new improved formula, this article analyses descending well feasibility of designed double-bent screw tool. This article analyses the sensitivity of bend angle/L $1 / \sigma / \mathrm{L}_{3}$ and at the same time gives the corresponding conclusions and recommendations, which will have certain theory guidance to fieldwork.
\end{abstract}

\section{Introduction}

Curved housing is a key tool screw drill directional wells and horizontal wells construction, which deflection rate meets the design requirements is the key to drilling directional and horizontal wells trajectory control success. Curved casing screw drill as early as 1985, began to study the H.Karisson et al., And made three fixed circle method. In 1990, B.R.Hassen et al proposed a dual radius method ${ }^{[1]}$. In 2004, Liu Xiushan put forword the improving methods for three given round, first considering the effects of structural angled position of the guiding hole deflection rate.

\section{Geometric deflection rate calculation}

When the results of the study are summarized in this paper, based on the principle of minimum potential energy, BHA-bottom hole assembly achieve stable mechanical equilibrium, drill lateral force will tend to zero, and the geometry of the BHA-bottom hole assembly determines the maximum tool of deflection rate (deflection rate limit). Under this paper for screw drilling tools in the sex was analyzed, and the maximum length of screw drill tool formula is given. Considering the gap between the stabilizer and the borehole drill double curved shell made affect the geometry of deflection rate, deflection rate of the additional impact of the gap gives the definition of improved geometry deflection rate formula, and the formula by which the influence of manufacturing several factors slope, its influence law in line with the actual site; analyzing factors at the same time gives a reasonable suggestion, can be made on-site guidance.

\subsection{Screw drill geometric deflection rate calculation}

Since the exposure of the bottom hole assembly and the borehole wall is irregular, the point of contact with the wall of the centralizer is dynamic, so the point on the circle usually stabilizer and the center line of the drill ${ }^{[2]}$. Because the field is often due to the use of the size of the centralizer ${ }^{[3-4]}$, centralizer and that there is a gap between the borehole, this will make the slope of the screw hole has a greater impact. Therefore, it is necessary to consider the impact of clearance on the screw hole made 
slope.

[5] consider the impact of the gap on the deflection rate formula,

$$
K=K_{\lambda}+K_{\sigma}=\frac{60}{L_{T}}\left(\lambda_{1} \gamma_{1}+\lambda_{2} \gamma_{2}\right)+\frac{10.8 \sigma}{\pi L_{S} L_{1}}
$$

$K_{\lambda}$ representation made double curve slope screw hole produced., $\left(^{\circ}\right) / 30 \mathrm{~m} ; \lambda_{1}$ represents angled position impact factor, which is equal to $\left(L_{3}+L_{4}\right) / L_{S} ; L_{s}$ represents the length between the two centralizers., $L_{S}=L_{2}+L_{3}+L_{4}, \mathrm{~m} ; \lambda_{2}$ represents angled position on impact factor, its value is equal to $L_{4} / L_{S} ; \gamma_{1}$ represents under the structure of double-bend corner screw drill, $\left(^{\circ}\right) ; \gamma_{2}$ represents structurally corner bend double screw drill, $\left({ }^{\circ}\right) ; L_{T}$ represents the total length of the drill whipstocking., $L_{T}=L_{1}+L_{s}, \mathrm{~m}$; $\sigma$ represents the stabilizer and the borehole gap., $\mathrm{mm}$; $K_{\sigma}$ represents a gap generated effects Additional deflection rate, ${ }^{\circ} / 30 \mathrm{~m}$ 。

[5] because of its simple formula is widely used, but (4) has two disadvantages: (1) between the two considered centralizer tool length $L_{S}$, but this is not comprehensive, total drill should whipstocking instead of the length $L_{T}$, the following will give proof; (2) when $\sigma$ gap is increased, deflection rate (4) calculated $\mathrm{K}$ also increased, but this does not meet the actual site. [4] noted that the steady wear and tear that is big gap will cause the ultimate curvature is reduced. And is also found in the relevant guide screw drill manual, curved casing screw drill pads add (reduce the gap) helps improve deflection rate. Therefore considers that the use of a (4) calculated from the slope of the limit made is not accurate, it is necessary to improve it.

\section{Improved gap on the impact of deflection rate formula}

In this paper, the principle of minimum potential energy that the screw drill down into the well due to the stiffness, deformation does not occur. Adding nearly stabilizer and the borehole gap $\sigma$, a black line indicates the position of the screw hole gap by affected.
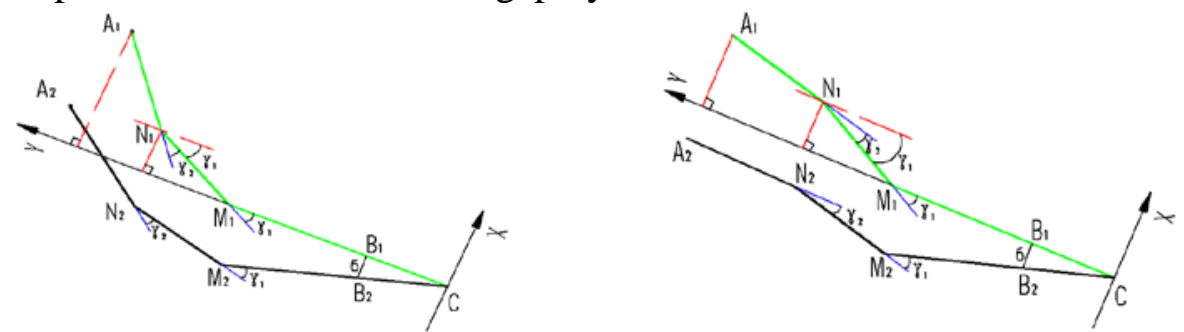

Fig.1 Sketch of accordant double-bent screw tool Fig.2 Sketch of reverse double-bent screw tool

Point $C$ represents the center of the drill, the first point is equivalent to $1 ; B_{i}\left(B_{1}\right.$ and $B_{2}$, similar to the following) represents the center of the stable, the equivalent of point $2, \mathrm{M}_{\mathrm{i}}$ represents the next bend point bend double screw drill; $\mathrm{N}_{\mathrm{i}} \mathrm{N}_{\mathrm{i}}$ represents the inflection point bend twin screw drill; $\mathrm{A}_{\mathrm{i}}$ represents the center point away from the drill centralizer, the equivalent of point 3. $\sigma$ represents $\mathrm{B}_{1}$, $\mathrm{B}_{2}$ distance between, $\beta$ represents a gap caused by the deviation angle, $\gamma_{1}$ represents the structure bends, $\gamma_{2}$ represents the structure corners. Additional deflection rates defined gap impact of $K_{\sigma}$ is equal to the gap offset the impact angle $\beta$ with three points of the arc length $\overparen{A_{i} C}$ ratio.

$$
K_{\sigma}=\frac{\beta}{\overparen{A_{i} C}} \bullet \frac{5.4}{\pi}
$$

For long radius horizontal well, whipstocking radius $\mathrm{R}$ is generally more than $100 \mathrm{~m}$, so the total length of the drill whipstocking $L_{\mathrm{T}}$ far less than R. Therefore, $\beta=\sigma / L_{1} ; \overparen{A_{i} C}=L_{T}$. It follows that the improvement of the formula (4) is,

$$
K=K_{\lambda}-K_{\sigma}=\frac{60}{L_{T}}\left(\lambda_{1} \gamma_{1}+\lambda_{2} \gamma_{2}\right)-\frac{5.4 \sigma}{\pi L_{1} L_{T}}
$$




\section{Sensitivity Analysis screw drill}

\subsection{Effects of structural corners of the deflection rate}

Holding $\mathrm{L}_{1}=1.15 \mathrm{~m}, \mathrm{~L}_{2}=0.81 \mathrm{~m}, \mathrm{~L}_{3}=4.27 \mathrm{~m}, \mathrm{~L}_{4}=1.2 \mathrm{~m}, \sigma=2 \mathrm{~mm}$ constant is calculated by the program derived $\gamma_{2}$ (angled structure, unit: $\left.{ }^{\circ}\right), \gamma_{1}$ (Under construction corner unit: ${ }^{\circ}$ ) different combinations (unit: ${ }^{\circ} / 30 \mathrm{~m}$ ).

Table1 the influence of bend angle on deflection rate in accordant double-bent screw tool

\begin{tabular}{|c|c|c|c|c|c|}
\hline & $-1.5^{\circ}$ & $-1.25^{\circ}$ & $-1.0^{\circ}$ & $-0.75^{\circ}$ & $-0.5^{\circ}$ \\
\hline $\begin{array}{l}1.75^{\circ} \\
1.5^{\circ} \\
1.25^{\circ} \\
1.0^{\circ} \\
0.75^{\circ}\end{array}$ & 9.59 & $\begin{array}{l}9.98 \\
8.22\end{array}$ & $\begin{array}{l}10.36 \\
8.60 \\
6.85\end{array}$ & $\begin{array}{l}10.75 \\
8.99 \\
7.23 \\
5.47\end{array}$ & $\begin{array}{l}11.13 \\
9.38 \\
7.62 \\
5.86 \\
4.10\end{array}$ \\
\hline
\end{tabular}

Data in Table 1 of the analysis the following results: (1) peer comparison, on the corner $\gamma_{2}$ decreasing to $0.25^{\circ}$ difference, deflection rate to $0.38^{\circ} / 30 \mathrm{~m}$ diminishing the difference; (2) Comparing column, under the corners $\gamma_{1}$ to $0.25^{\circ}$ decrements, build rate to $1.76^{\circ} / 30 \mathrm{~m}$ of decrements; (3) $\gamma_{1}-\gamma_{2}$ difference is $0.25^{\circ}\left(0.5^{\circ} 、 0.75^{\circ} 、 1^{\circ}\right)$, the decreases corners, build rates are $2.15^{\circ} / 30 \mathrm{~m}$ diminishing the difference.

Table2 the influence of bend angle on deflection rate in reverse double-bent screw tool

\begin{tabular}{|c|c|c|c|c|c|}
\hline & $-1.5^{\circ}$ & $-1.25^{\circ}$ & $-1.0^{\circ}$ & $-0.75^{\circ}$ & $-0.5^{\circ}$ \\
\hline $\begin{array}{c}1.75^{\circ} \\
1.5^{\circ} \\
1.25^{\circ} \\
1.0^{\circ} \\
0.75^{\circ}\end{array}$ & 9.59 & $\begin{array}{l}9.98 \\
8.22\end{array}$ & $\begin{array}{l}10.36 \\
8.60 \\
6.85\end{array}$ & $\begin{array}{c}10.75 \\
8.99 \\
7.23 \\
5.47\end{array}$ & $\begin{array}{c}11.13 \\
9.38 \\
7.62 \\
5.86 \\
4.10 \\
\end{array}$ \\
\hline
\end{tabular}

The data in Table 2 analyzes the following results: (1) peer comparison, the difference between the corner $\gamma_{2}$ to $0.25^{\circ}$ increments, deflection rate to $0.38^{\circ} / 30 \mathrm{~m}$ difference between the increment;(2) the same column comparison, the following elbow $\gamma_{1}$ to $0.25^{\circ}$ decrements, build rate to $1.76^{\circ} / 30 \mathrm{~m}$ diminishing the difference; (3) $\gamma_{1}+\gamma_{2}$ value of $0.25^{\circ}\left(0.5^{\circ} 、 0.75^{\circ} 、 1^{\circ}\right)$, the corners $\gamma_{1}$ decreases the build rates are $1.37^{\circ} / 30 \mathrm{~m}$ diminishing the difference.

Table 1 compares and transverse to Table 2, the results are as follows:(1) by (1) and (2) compare results obtained, under the influence of the corners $\gamma_{1}$ build rate is 4.6 times the upper corners $\gamma_{2}$. Thus, under the influence of bends on deflection rate it is very significant, realistic scene.(2) by (3) analysis of the results obtained, deflecting tools for making the difference between the two corners of diminishing the value of the slope is not affected, which can be used to quickly obtain two screw tool combination of any structure bends deflection rate.

\subsection{The influence to deflection rate of $L 1($ the distance of the stabilizer and the bit)}

Using control variable method, keep the $\mathrm{L}_{2}=0.81 \mathrm{~m} 、 \mathrm{~L}_{3}=4.27 \mathrm{~m} 、 \mathrm{~L}_{4}=1.2 \mathrm{~m} 、 \gamma_{1}=1.5^{\circ} \quad\left(\gamma_{1}=1.75^{\circ}\right)$ 、 $\gamma_{2}= \pm 1^{\circ} 、 \sigma=2 \mathrm{~mm}$ unchanged. Consider the case of the gap, deflection rate to draw double-screw bending tools K and L1 relationship graph. Reference range chart L1 under the Shengli Oilfield stabilizer used in horizontal wells range from the drill bit ${ }^{[6]}$, and this will be based on an appropriate range of relaxing, ranging from $0.2 \mathrm{~m}$ to $2.0 \mathrm{~m}$.

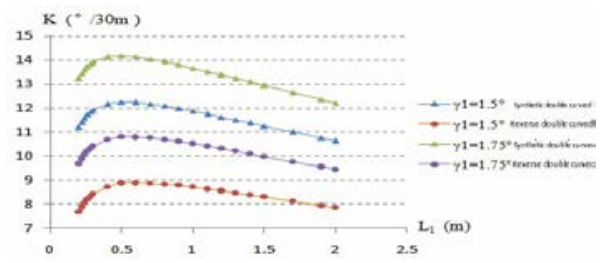

Fig3. relationship graph of deflection rate $\mathrm{K}$ with $\mathrm{L}_{1}$

(1) when $L_{1}$ is less than $0.5 \mathrm{~m}$, deflection rate of double-screw bending tools $\mathrm{K}$ increases $\mathrm{L}_{1}$ is a 
sharp increase; When $L_{1}$ is greater than $0.5 \mathrm{~m}$, deflection rate twin-screw bending tools $\mathrm{K}$ increases $\mathrm{L}_{1}$ is gradually reduced; (2) both with twin curved or bent double reverse curve has a corresponding optimal deflection rate. Two best deflection rate corresponding $\mathrm{L}_{1}=0.5 \mathrm{~m}$. Therefore, under the influence of a gap considering the case, in theory, $\mathrm{L}_{1}$ should be selected about $0.5 \mathrm{~m}$. But between the drill bit and Down stabilizer typically placed inclinometer instrument, it is generally in the field $L_{1}$ is selected $1 \mathrm{~m} \sim 1.5 \mathrm{~m}$.

\subsection{The influence to deflection rate of $\sigma$ (the gap of the stabilizer and the wall)}

$\mathrm{L}_{1}=1.15 \mathrm{~m} 、 \mathrm{~L}_{2}=0.81 \mathrm{~m} 、 \mathrm{~L}_{3}=4.27 \mathrm{~m} 、 \mathrm{~L}_{4}=1.2 \mathrm{~m} 、 \gamma_{1}=1.5^{\circ} 、 \gamma_{2}= \pm 1^{\circ}$ maintained unchanged. Consider the case of the gap, deflection rate $\mathrm{K}$ and $\sigma$ draw a graph of twin-screw bending tools. Fig $4 \sigma$ range is $0.5 \mathrm{~mm}$ to $8 \mathrm{~mm}$.

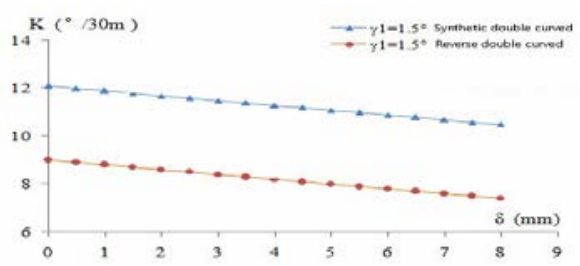

Fig.4 relationship graph of deflection rate $\mathrm{K}$ with $\sigma$

For the same forward and backward curved double-screw deflecting tool, when the stabilizer and the borehole wall gap $\sigma$ increases, deflection rate $\mathrm{K}$ is linear reduction. This is the actual situation is consistent. In order to ensure the deflecting when deflection rate does not change, high wear-resistant materials must be stable, a steady reduction in the wear and tear. Conversely, the material can be easy to wear centralizer to increase the gap, reducing tool deflection rate.

\subsection{Influence distance $L_{3}$ between the two corners of the deflection rate}

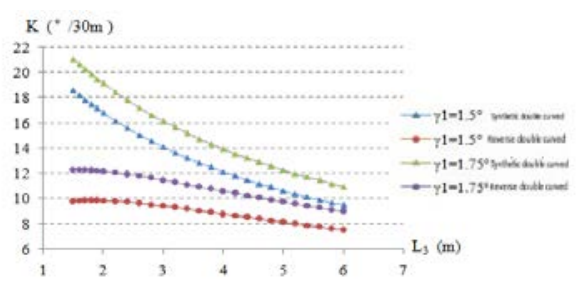

Fig. 5 relationship graph of deflection rate $\mathrm{K}$ with $\mathrm{L}_{3}$

Using control variable method, keep the $\mathrm{L}_{1}=1.15 \mathrm{~m} 、 \mathrm{~L}_{2}=0.81 \mathrm{~m} 、 \mathrm{~L}_{4}=1.2 \mathrm{~m} 、 \gamma_{1}=1.5^{\circ} \quad\left(\gamma_{1}=1.75^{\circ}\right)$ 、 $\gamma_{2}= \pm 1^{\circ} 、 \sigma=2 \mathrm{~mm}$ unchanged. Consider the case of a gap, with the draw to build double-bend and reverse slope twin-screw bending tools $\mathrm{K}$ and L3 of curve. $\mathrm{L}_{3}$ figure ranges from $1.5 \mathrm{~m}$ to $6 \mathrm{~m}$. Calculated at $\mathrm{K}=19^{\circ} / 30 \mathrm{~m}$, the maximum length of the screw drill $\left(\mathrm{L}_{\mathrm{T}}\right)_{\max }=5.7 \mathrm{~m}$, while $\mathrm{L}_{\mathrm{T}}=4.61 \mathrm{~m}$; In the $\mathrm{K}=8^{\circ} / 30 \mathrm{~m}$ when, $\quad\left(\mathrm{L}_{\mathrm{T}}\right)_{\max }=8.77 \mathrm{~m}$, while $\mathrm{L}_{\mathrm{T}}=8.36 \mathrm{~m}$. Therefore, the design of the screw tool can smoothly into the next.

(1)For screw reverse double curve tool, recommended distance between the two corners $\mathrm{L}_{3}=2 \mathrm{~m}$ have a higher deflection rate; when $\mathrm{L}_{3}$ is greater than $2 \mathrm{~m}$, which made approximately linear slope gradually decreased.(2)For the same twin-screw bending tools, deflection rate $\mathrm{K}$ increases $\mathrm{L}_{3}$ is reduced; By curve fitting, logarithmic function $K=A \ln \left(L_{3}\right)+B$ satisfies the relationship, the correlation coefficients were 0.999 , where A, B are parameters.

\section{Examples of calculated field}

Liaohe Oilfield using "Jing 33- Ce Ping 71" casing sidetrack horizontal well data, the use of screw drill model 5LZ95 $\times 7$ Y7. The basic parameters are given screw hole: $\mathrm{L}_{1}=1.13 \mathrm{~m} 、 \mathrm{~L}_{2}=0.13 \mathrm{~m}$ 、 $\mathrm{L}_{3}=2.8 \mathrm{~m} 、 \mathrm{~L}_{4}=0.3 \mathrm{~m} 、 \gamma_{1}=3^{\circ} 、 \gamma_{2}=1.8^{\circ}$ 。WOB control in $50 \sim 70 \mathrm{kN}$, gap $\sigma=2 \mathrm{~mm}$. 
Table3 first example for deflection rate calculating

\begin{tabular}{|c|c|c|c|c|c|}
\hline $\begin{array}{l}\text { Depth } \\
\text { m }\end{array}$ & $\begin{array}{l}\text { deflection } \\
\text { rate } \\
/ 30 \mathrm{~m}\end{array}$ & $\begin{array}{l}\text { [4] deflection rate } \\
\text { calculation } / 30 \mathrm{~m}\end{array}$ & $\begin{array}{c}\text { error } \\
\%\end{array}$ & $\begin{array}{c}\text { calculation } \\
\text { deflection rate In } \\
\text { this paper } / 30 \mathrm{~m}\end{array}$ & $\begin{array}{c}\text { error } \\
\%\end{array}$ \\
\hline$\underset{3}{2088.18-2092.6}$ & 36.9 & & $\begin{array}{c}18.7 \\
3\end{array}$ & & 11.71 \\
\hline $\begin{array}{c}2093.01-2095.6 \\
1\end{array}$ & 39.3 & 43.81 & $\begin{array}{c}11.4 \\
8\end{array}$ & 41.22 & 4.88 \\
\hline $\begin{array}{c}2098.63-2106.3 \\
6\end{array}$ & 38.1 & & $\begin{array}{c}14.9 \\
9\end{array}$ & & 8.19 \\
\hline
\end{tabular}

Examples of verification obtained by the above, this article through improved built precision slope formula than the original ([4]) and high precision, small error. Description Improved Formula deflection rate more in line with the actual site.

\section{Conclusion}

(1) In the design of the drilling tool in the guidedeflection rate is the main reference. In this paper, three amendments to borrow on the basis of the principle of a given circle of deflection rate under the influence of the gap geometry formula was improved, improved accuracy, by way of example to verify compliance with the actual site.

(2) Based on the improved formula on the corners of the structure of the screw hole next to the stabilizer from the drill bit, a stable with the wall of the gap, the sensitivity of the distance between the two corners to make the corresponding analysis, draw the corresponding conclusions have substantial on-site work has a certain theoretical guidance.

\section{References}

[1] Birades M and Fenoul R.A Mieroeomputer Program for Predietion of Bottomhole Assembly Trajeetory.SPE15285

[2] Xiushan Liu, Practical calculation method of built the guide hole geometrical slope[J]. Gas Industry,2005,25 (11):50-52.

[3] Xiushan Liu, Chengping Wang, Chenan Lin, Curved casing screw drill design method[J]. Oil Drilling \& Production Technology,2005,27(4):19-23.

[4] Xueping, Tang,Zuxi, Chen,Guangtai Wang et. Prediction Methods drillbuilt rate screw short radius horizontal well[J]. Oil Drilling \& Production Technology,

[5] Xiushan Liu, Shushan He, Ye Zhou. Study guide drill geometry built slope[J]. Acta Petrolei Sinica,2004, 25(6):83-87.

[6] Baoxin Wang, Daiwen Xu, Cunzhi Chen. Power drill curved shell built of geometric analysis and calculation of rate[J]. Oil Drilling \& Production Technology, 1994,16(1):32-37. 